Article

\title{
Dietary Practices Associated with Obesity among Babcock University Students in Ilishan-Remo, Ikenne Local Government Area, Ogun State, Nigeria
}

\author{
Ogechukwu E. Okondu ${ }^{1,2}$, Chibuenyim C. Ogueri ${ }^{3}$, Ayomide R. Afolabi ${ }^{4}$ and Uchenna L. \\ Ifediora ${ }^{5}$ \\ 1 Department of Public Health, Babcock University, Ilishan-remo, Ogun State, Nigeria; \\ okonduo@babcock.edu.ng \\ 2 Department of Human Kinetics and Health Education, Nnamdi Azikiwe University, Awka, Anambra \\ State, Nigeria \\ 3 Department of Special Projects, Federal Ministry of Health, Federal Secretariat Complex, Podium B \\ Phase III Ahmadu Bello Way, Central Area Garki-Abuja, Nigeria \\ 4. Department of Public Health, Babcock University, Ilishan-remo, Ogun State, Nigeria \\ 5. Department of Human Kinetics and Health Education, Nnamdi Azikiwe University, Awka, Anambra \\ State, Nigeria
}

\footnotetext{
* Correspondence: Department of Public Health, Babcock University, Ilishan-remo, Ogun State, Nigeria; okonduo@babcock.edu.ng, Tel: 07085779565
}

\begin{abstract}
Obesity is an issue of public health concern as it contributes to chronic non-communicable diseases despite the fact that it is preventable. Dietary practices and environment have been associated with increased risk of cardiovascular diseases, hypertension, overweight and obesity among young people. This study aimed to assess the dietary patterns associated with obesity among Babcock University students. A descriptive cross-sectional study was used to obtain data from 391 participants. Results reveal respondent's knowledge was $12.06 \pm 2.3$ translating to an $80 \%$ prevalence performance, level of perception was $37.23 \pm 9.23$ with prevalence of $59.0 \%$, dietary practices was $19.6 \pm 5.23$ with $59 \%$ prevalence. Factors influencing dietary practices revealed mean score of $15.2 \pm 4.5$ with $72.3 \%$ prevalence performance. The factors identified in this study has a great influence on dietary practices of the study participants. In conclusion Babcock University students have an excellent knowledge of dietary practices related to obesity. They also had good dietary practices. The identified factors had a great influence on the study participants.
\end{abstract}

Keywords: Obesity, Dietary practices, Diabetes, Cardiovascular, Hypertension

\section{Introduction}

Obesity is a serious public health issue and a leading cause of morbidity and mortality worldwide despite the fact that it is preventable. The prevalence is increasing in both developed and developing countries and it is estimated that by the year 2030, 1.12 billion people across the globe will be obese [1]. Obesity accounts for $16 \%$ of the global disease burden and increases the risk of developing noncommunicable diseases such as diabetes, heart diseases, high blood pressure and cancer [1,2,3]. Noncommunicable diseases are the largest contributors to death all over the world [4].

Among young adults, obesity is also on the rise and has been linked to sedentary lifestyles, decreased physical activity, urbanization and modernization in dietary practices which includes increased intake of processed food like beef, refined grains etc. [4,5,6,7]. Unhealthy dietary practices lead to changes in the body's makeup, biochemical and inflammatory diseases [8]. Various studies have linked dietary practices to obesity and development of chronic diseases $[9,10,11]$. The number of university students living with overweight and obesity in developing countries is $11 \%$ in India, 20- 
$30 \%$ in Malaysia, $10.8-24 \%$ in South Africa and $10.8 \%-24 \%$ in Nigeria [12]. Studies have revealed that eating healthy foods such as fruits, green vegetables, whole grains, lean meat and foods rich in fibre can promote the general well-being of an individual and prevent obesity [13].

This study aimed to identify the risk factors that are linked with obesity among Babcock University students.

\section{Materials and Methods}

\subsection{Study Design}

A descriptive cross sectional study which aimed at assessing dietary practices associated with obesity among students. It used the quantitative method of data collection to measure the influence of dietary practices on obesity.

\subsection{Description of study area and population}

Babcock University is a Seventh Day Adventist Institution of higher learning, located in Ilishan Remo Ogun State, Nigeria. It is within Ikenne local government area. The university has 9 schools and one college. These includes: School of Agricultural sciences, School of Basic and Applied Sciences, School of Computing and Engineering Sciences, School of Education and Humanities, School of Law and Security studies, School of Nursing Sciences, School of Public and Allied Health, Babcock Business School, School of Post Graduate Studies and Benjamin Carson College of Medicine.

The study focused on undergraduate students of Babcock University. This includes both male and female students from the 9 schools. All undergraduate students were included in this study. The levels that were included were 100 level to 500 level. As at last year the population of Babcock University was 8871 in the main campus. This was gotten from student development division.

\subsection{Data Collection and Analysis}

A structured questionnaire was developed to collect data for this research. The instrument was pretested with $10 \%$ of the sample size from a similar population. Participants were selected using the multistage sampling and respondents were administered the question under the supervision of a trained research assistant. Respondents were instructed not to write their names or any form of identification on the questionnaire to ensure anonymity.

Knowledge on obesity was computed on a 15-point rating scale, perceived dietary practices associated with obesity was measured on a 63-point scale with sub scale; perceived susceptibility measured on 21-point rating scale, perceived benefit of obesity health related information measured on a 21-point rating scale and perceived modifying factors on dietary practices were measured on 21point rating scale.

The data that was gotten from this study was analysed using computable assisted Software Statistical Package for Social Science version 21.0. Data was reported using frequency distribution of the respondents, descriptive statistics of means and standard deviation and correlation, regression to test associates between variables. (Babcock University Health and Research Ethics: NHREC/24/01/2018).

\section{Results}

\subsection{Socio-demographic characteristics of respondents}

The study revealed that the mean age of respondents was 19.2 \pm 2.0 . Majority of the respondents were females $(64.7 \%)$ while males (35.3\%). Most of the respondents were of Yoruba (47.6\%) origin, 
Igbo (31.5\%), Hausa (4.9\%) and other minority group (16.2\%). Of the respondents, $83.9 \%$ were Christians, $14.8 \%$ were Islam (14.8\%) and $1.3 \%$ belonged to other religion. Results also reveal that $15.6 \%$ of the respondents were in 100 level, $12.8 \%$ were in 200 level, $25.8 \%$ were in 300 level, $38.6 \%$ were in 400 level and $7.26 \%$ were in 500 level. (See Table 1 for details)

Table 1: Socio-demographic characteristics of respondents

\begin{tabular}{|c|c|c|}
\hline \multirow{2}{*}{ Socio-demographic variables for consideration } & \multicolumn{2}{|c|}{ Respondents in this study; $\mathrm{N}=391$} \\
\hline & \multirow[t]{2}{*}{ Frequency $(\mathrm{n})$} & \multirow[t]{2}{*}{ Percentage (\%) } \\
\hline 1. Age (in years) $\overline{x(S D)} 19.2 \pm 2.02$ & & \\
\hline \multicolumn{3}{|l|}{ 2. Gender: } \\
\hline Male & 138 & 35.3 \\
\hline Female & 253 & 64.7 \\
\hline \multicolumn{3}{|l|}{ 3. Ethnic group } \\
\hline Yoruba & 186 & 47.6 \\
\hline Igbo & 123 & 31.5 \\
\hline Hausa & 19 & 4.90 \\
\hline Other & 63 & 16.2 \\
\hline \multicolumn{3}{|l|}{ 4. Religion } \\
\hline Christian & 328 & 83.9 \\
\hline Muslim & 58 & 14.8 \\
\hline Others & 5 & 1.3 \\
\hline \multicolumn{3}{|l|}{ 5. Class (levels) } \\
\hline 100 & 61 & 15.6 \\
\hline 200 & 50 & 12.8 \\
\hline 300 & 101 & 25.8 \\
\hline 400 & 151 & 38.6 \\
\hline 500 & 28 & 7.2 \\
\hline
\end{tabular}

\section{2. Knowledge distribution}

Knowledge on Obesity among respondents measured on a 15 point rate scale reported a mean score of $12.06(0.12) \pm 2.3$, translating to a $80 \%$ prevalence performance for group knowledge.

\subsection{Perceived dietary practices associated with obesity}

Level of perceived dietary practices among respondents measured on a 63 point rating scale reported a mean score of $37.23(0.40) \pm 9.23$, translating to a $59.0 \%$ prevalence performance for the study group

\subsection{Dietary Practices}

Dietary practices among study respondents measured on a 33 point rating scale reported a mean score of $19.6(0.26) \pm 5.23$, translating to a $59 \%$ prevalence performance representing those that have good dietary practice 


\subsection{Factors Associated with Dietary Practices}

Factors influencing dietary practices among the study participants measured on a 21 point rating scale reported a mean score of $15.2(0.23) \pm 4.5$, translating to a $72.3 \%$ prevalence performance. The factors identified in this study has a great influence on dietary practices of the study participants

Table 2: Descriptive characteristics of composite score of respondents

\begin{tabular}{|l|l|l|l|l|}
\hline \multirow{2}{*}{ Variables } & \multirow{2}{*}{$\begin{array}{c}\text { Scale of Measure } \\
\text { reference }\end{array}$} & $\begin{array}{l}\text { Respondents in this } \\
\text { study, N=391 }\end{array}$ & \multirow{2}{*}{ Prevalence } \\
\cline { 3 - 4 } & & $(\bar{x})(\mathrm{SE})$ & $\pm \mathrm{SD}$ & \multicolumn{1}{|c|}{$\mathbf{8 0 . 1}$} \\
\hline Level of Knowledge & 15 & $12.02(0.12)$ & 2.39 & $\mathbf{5 9 . 0}$ \\
\hline $\begin{array}{l}\text { Perceived dietary practices } \\
\text { associated with obesity }\end{array}$ & 63 & $37.2(0.40)$ & 9.39 & $\mathbf{5 9 . 4}$ \\
\hline Dietary Practices & 33 & $19.6(0.26)$ & 5.23 & $\mathbf{7 1 . 4}$ \\
\hline $\begin{array}{l}\text { Factors associated with dietary } \\
\text { practices }\end{array}$ & 21 & $15.2(0.23)$ & 4.58 & \\
\hline
\end{tabular}

\section{Discussion}

This study shows that most of the participants were females and majority of them were young adults between the ages of 19-20years. This is because, young adults are mostly found in tertiary institutions as undergraduate students. According to a study by [14], young adulthood was defined as the period when the adolescent complete secondary school education and enter the tertiary institution. Most of the respondents were female and they are from the Yoruba ethnic group because the university which is Babcock University is situated in a Yoruba Community and it has higher population of girls than boys. Socio-demographic factors and lifestyle can influence obesity [15].

This study discovered that quite a number of the respondents have heard about obesity and also know that obesity can be prevented. [6] pointed out that most individuals know that overeating and lack of exercise contribute to obesity. Overweight and obesity is determined by individual factors and risky behaviours [11]. However, very few individuals know about their body mass index (BMI) and can be able to measure it. In another study that was carried out by [2], they discovered that twothird of the participants had good knowledge of obesity. A large number of the respondents consider obesity to be hereditary and also a risk factor for non- communicable diseases. Overweight and obesity arises from the interaction of genetic, environmental and lifestyle factors and also that obesity is a risk factor for non- communicable diseases like diabetes type 2, heart diseases, high blood pressure dyslipidemia and some types of cancer [16]. Many undergraduate students know that obesity can be influenced by sedentary life style. A study carried out by [13], shows that the prevalence of obesity and overweight can be reduced by increased physical activity. 
Common dietary practices were measured among the undergraduate students and this indicated that, majority of them consume fruits and a large number of them also admitted that they don't eat fruits daily, others ate legumes and vegetables frequently. It also showed that most of them consumed vegetables more than 3 times per week. Many of these students get their food from the university cafeteria and superstore. University undergraduate students adopted unhealthy eating behaviour due to reduced availability, affordability and accessibility to healthy diet in the university [14]. Perceived constraints and convenience strongly influences adolescent food choices [17]. Adolescents also indicated that they preferred to eat food at restaurants because the food was served quickly. More than half of them take balanced diet. Most of them also consumed a lot of carbonated drinks and ate in between meals and more of snacks. Research has shown that consumption of sugar sweetened beverages and fast food is higher among young adults than among older adults among black Americans [16]. In a carried out by [18], the first five foods consumed by the participants were buggers, pizza, fried chicken, fries and grilled chicken. Soft drink was the most popular beverages chosen by more than half of this population. These finding are very important because of the association of soft drink consumption with increased energy and low calcium intake.

Most undergraduates, perceived healthy eating to be a choice of preventing obesity. Others believe that healthy foods like vegetables and whole grains will not lead to obesity. Similarly, a study carried out by [14], confirms that consumption of vegetables and legumes are linked to prevention of several chronic diseases in adulthood. More so, a Mediterranean diet such as mono saturated fatty acid fruits, whole grains and cereals may protect against obesity [6]. Despite the excellent knowledge found in our study, a small number of undergraduates said they could not differentiate between healthy and unhealthy foods. Lack of knowledge of healthy food choices has negative influence in eating habits and nutritional status of university students [12]. Most of these students also prefer taking water instead of carbonated drinks. According to [10], the consumption of carbonated drink is very high across the globe. However, many of them also believe that eating late at night can lead to obesity. Taking meals at late hours is a contributing factor to weight gain and obesity [18].

Perceived benefit of health related information in forming dietary practices among undergraduates was moderate. There is lack of information, in not only the health consequences of obesity but also the benefit of lifestyle modification. Information is power there is need to increase the knowledge of people on obesity and its health consequences [19]. Half of them had good perception of the benefit while very few of them, had an excellent perception on the benefit from health information on dietary practices. Perceived modifying factors identified includes restriction in schools allow most participants to eat as much as they want to. The environment is the major reason that influences their eating habit while in most of the undergraduates; the availability of food determines how food is eaten. Students select fast food due to its palatability, availability and convenience [14].

The study result revealed that most of the undergraduates, believe that obesity is hereditary. A large number of them also perceive obesity to be linked with childhood eating habits. It is important to give children a healthy start in life at an early age, by making them cultivate healthy eating habits and encouraging them to engage in a lot of physical activity. Prevention of childhood obesity can reduce the prevalence of obesity in adulthood [20]. While almost all of them linked obesity to lack of physical activity. Research has shown the important function of physical activity in preventing obesity and the diseases associated with it should be put into consideration when planning future 
health interventions [13]. Stress related eating habit is a major determinant for obesity. A study carried out among college students by [14] pointed out that people living in stressful society tend to eat more as a way of coping with stress. Most of these undergraduates consume snacks regularly and also ate in between meals because of the environment he or she found herself or himself. A large number of factors affect food choices including economic, environmental, psychological and cultural factors [17]. Urbanization and westernization are linked to reduced level of physical activity and increased food supply, which includes access to high calorie foods and sugar sweetened beverages [21]. Changing dietary habits and physical activity pattern is due to modernization and technological advancement [22]

Hypothesis: There is no significant relationship between the level of obesity knowledge and dietary practices.

There is no significant relationship between the level of obesity knowledge and dietary practices of the respondents. Using a correlation, there is a relationship between the knowledge on obesity and dietary practices computed. Therefore, we reject the null hypothesis which says there is no significant relationship between the level of knowledge of obesity and dietary practices. We therefore accept the alternative hypothesis (H1) which says there is a significant relationship between the level of knowledge of obesity and dietary practices of respondents. There is a significant association between nutrition knowledge and dietary practices [23].

\section{Conclusions/Recommendations}

In conclusion Babcock University students have an excellent knowledge of dietary practices related to obesity and good dietary practices. This results are not surprising as Babcock University is a faith-based institution owned by Seventh Day Adventist known for Good Dietary practices with emphasis to Vegetarian diets practice. However, some of the students are not self-sufficient (selfefficacy) with regards to BMI measurement which is a key factor to understanding body mass and a major indicator for obesity and diabetes. The public health implications of this study are

- Public health policies should promote health education and healthy dietary practices among young adults. There is serious need for the implementation of wide approaches to reduce diseases associated with obesity among university students.

- Dietary practices of young people should be of public health concern because there is a direct relationship between inadequate diet at this early age and obesity.

- The findings from this study will warrant institutions to reduce the rising trend of obesity and overweight among young adults. This could be achieved by including health education and physical activity programs into the general study curriculum offered in most Nigerian Universities. 
6. Supplementary Materials:

Table 3. Perception of Respondents on the possible causes of Obesity

\begin{tabular}{|l|l|l|}
\hline \multirow{2}{*}{ Statements for Consideration } & \multicolumn{2}{|l|}{ Respondents in this study N=391 } \\
\cline { 2 - 4 } & Frequency (n) & Percentage (\%) \\
\hline Obesity is hereditary & 312 & 79.8 \\
\hline $\begin{array}{l}\text { Childhood eating habits is the main determinants of } \\
\text { Obesity in adulthood }\end{array}$ & 292 & 75.3 \\
\hline Lack of physical activity can contribute to obesity & 339 & 86.7 \\
\hline Stress related eating habits & 348 & 89.1 \\
\hline High intake of calorie foods & 329 & 84.2 \\
\hline $\begin{array}{l}\text { Environment has a role in determining our food } \\
\text { practices }\end{array}$ & 334 & 85.4 \\
\hline Eating in between meals & & 84.9 \\
\hline
\end{tabular}

Table 4. Dietary Practices among respondents for correct responses (very often and sometimes)

\begin{tabular}{|l|l|l|}
\hline \multicolumn{1}{|c|}{ Statements for Consideration } & Respondents in this study N=391 & \\
\cline { 2 - 3 } & Frequency (n) & $\begin{array}{l}\text { Percentage } \\
(\%)\end{array}$ \\
\hline I eat fruits always & 258 & 66.0 \\
\hline I eat at school cafeteria & 310 & 79.3 \\
\hline I eat balanced diet & 258 & 66.0 \\
\hline I take carbonated drinks & 262 & 67.0 \\
\hline Breakfast is the most important meal & 298 & 76.2 \\
\hline I eat breakfast & 244 & 62.4 \\
\hline I avoid some foods for health reasons & 242 & 61.6 \\
\hline I eat vegetables & 200 & 51.1 \\
\hline I eat a lot of fried foods & 218 & 55.7 \\
\hline I in between meals & 255 & 65.2 \\
\hline
\end{tabular}


Author Contributions: Conceptualization/supervision, data analysis, manuscript formatting ${ }^{1,2}$; Coinvestigator/data collection, writing, ${ }^{3}$; manuscript development, editing, visualization ${ }^{4}$; and manuscript development, editing and visualization ${ }^{5}$;

Funding:: "This research received no external funding"

Acknowledgement: We acknowledge the support of all authors

Conflicts of Interest: “The authors declare no conflict of interest."

\section{References}

1. Akarolo-Anthony, S.; Willet, W.; Spiegelman, D. Obesity epidemic has emerged among Nigerians. BMC Public Health 2014, 14, 455.

2. Adeleke, S.; Abioye-Kuteyi, E.; Sikuade, O.; Olusayo, A. Knowledge of Obesity Among the staff of the International Institute of Tropical Agriculture, Nigeria. International Journal Cur Rev. 2015,7(22).

3. Lerma-Cabrera, J.; Carvajal, F.; Lopez-Legarrea, P. Food addiction as a new piece of the obesity Framework. Nutr J. 2016,15:5.

4. Skaal, L.; Pengpid, S. Obesity and health workers: do healthcare workers care of themselves? SAMJ, S. Afr. Med 2011, 53(6), 563-567.

5. Moghimi-Dehkordi, B.; Safaee, A.; Vahedi, M.; Pourhoseingholi, A.; Pourhoseingholi, M.; Ashtaris, S.; Zali, M. Overweight and Obesity related factors in Urban Iranian Population Aged Between 20 to 84 years. Ann Med Health Sci Res. 2013, 3(1).

6. Naja, F.; Hwalla, N.; Hani, L.; Salem, M.; Azar, S.; Zeidani, M.; Nasreddine, L. Dietary patterns and odds of Type 2 diabetes in Beirut, Lebanon: a case-control study. Nutr. Metab 2012, 9:111.

7. Little, M.; Humphrie, S.; Patel, K.; Dewey, C. Factors associated with underweight, overweight and obesity among adults in a population of Rural South India: a cross sectional; study. BMC Obes 2016, 3:12.

8. Rocha, N.; Milagres, L.; Longo, G.; Ribeiro, A.; Novaes, J. Association between dietary pattern and cardiovascular risk in children and adolescents: a systematic review. Journal of Pediatria (Rioj) 2017, 93(3), 214-222.

9. Amin, F.; Syeda, I, N.; Gilani, A. Prevalence of Obesity and Overweight, its clinical markers and associate factors in a high risk South - Asian population. BMC Obes 2015, 2:16.

10. Kessaram, T.; Mckenzie, J.; Grini, N.; Merilles, O.; Pullar, J.; Roth, A.; White, P.; Hoy, D. Overweight, Obesity, Physical activity and sugar sweetened beverages consumption in adolescents of Pacific Islands: results from Global School based Student Health Survey and the Youth Risk Behaviour Surveillance System. BMC Obes 2015, 2:34.

11. El-kassas, G.; Itani, L.; Ali, Z. Obesity Risk Factors among Beirut Arab University Students in TripoliLebanon. Journal of Nutrition and Food Sciences 2015, 5:6.

12. Ukegbu, P.; Uwaebgute, A.; Echendu, C.; Ejike, C.; Anyika-Elekeh, J.; Asumugha, V.; Kuyik, S.; Omodamiro, S.; Nwofia, B.; Uzokwe, C.; Oluchi-Nliam, C.; Uwakwe, N. Obesity and associated factors in young adults attending tertiary institutions in South-eastern Nigeria. $S$ Afr J Clin Nutr. 2017, 30(2): 43-48.

13. Mogre, V.; Aleyira, S.; Nyaba, R. Factors Associated with central overweight and Obesity in Students attending the University for Development Studies in Tamale, Ghana: a cross-sectional study. S Afr J Clin Nutr 2014, 15.

14. Ganasegeran, K.; Al-Dubai, S.; Qureshi, A.; Al-abed, A. R.; Aljunid, S. Social and Psychological factors affecting eating habits among University students in a Malaysian medical school: a cross- sectional study. Nutr J. 2012, 11:48.

15. Gutierrez-Pliego, L.; Camarillo-Romero, E.; Montenegro-Morale, L.; Garcia, J. Dietary patterns associated with body mass index (BMI) and lifestyle in Mexican adolescents. BMC Public Health 2016, 16: 850. 
16. Van, M.; Steyn, N.; Marais, M. Characteristics and factors influencing fast food intake of young adult's consumers in Johannesburg, South Africa. S Afr J Clin Nutr 2016 23(3): 124:130.

17. Bogg, D.; Rosenberg, L.; Coogan, P.; Makambi, K.; Adams-Campbell, L.; Palmer, J. Restaurant foods, sugarsweetened soft drinks and obesity risk among young African women. Ethn Dis 2013, 2394, 445-451.

18. Obirikong, Y., Obirikong, Z.; Enoch, E.; Acheampong, P.; Tuboseiyefah, M.; Emmanuella, N. Prevalence and risk factor of obesity among practising nurses at three selected hospitals in Kumasi Metropolis, Ghana. Journal of Medical and Biomedical Sciences 2016, 5(3), 45-55.

19. Amadi, I.; Nwankwo, B.; Ugwu, V. Obesity in Adult Nigerians: A study of its pattern and Common Primary co- morbidities in rural Mission Gender Hospital in Imo State, South-eastern Nigeria. Nigerian Journal of Clinical Nutrition 2017, 14 (2).

20. Kristen, A.; Marais, D.; Schubul, C. The influence of socio-demographic factors on the nutritional status of children in the Stellen area, Western Cape. S Afr J Clin Nutr 2013, 26(3), 124-131.

21. Okafor, C.; Gezawa, I.; Sabir, A.; Raimi, T.; Enang, O. Obesity, Overweight and Underweight among urban Nigerians. Niger. J. Clin. Pract 2014, 7(6).

22. Goon, D.; Maputle, S.; Olukoga, A.; Lebese, R.; Khoza, L.; Ayanwu, F. Overweight, Obesity and underweight in Vhembe and Capricorn districts Limpopo. S Afr J Clin Nutr 2013, 26(3), 147-149.

23. Mushonga, N.; Mujuru, H.; Nyanga, L.; Nyaguru, S.; Musaka, N.; Demba, R. Parental Knowledge, Attitude and Practice Regarding Pre-school Children in Rural Zimbabwe. S Afr J Clin Nutr 2017, 17(4). 